Advances in Geosciences, 6, 103-110, 2006

SRef-ID: 1680-7359/adgeo/2006-6-103

European Geosciences Union

(c) 2006 Author(s). This work is licensed

under a Creative Commons License.

\title{
Impact of global warming on ENSO phase change
}

\author{
W. Cabos Narvaez, F. Alvarez-Garcia, and M. J. OrtizBeviá \\ Departamento de Física, Universidad de Alcala 28871 - Alcala de Henares, Madrid, Spain \\ Received: 28 June 2005 - Revised: 31 October 2005 - Accepted: 14 November 2005 - Published: 9 January 2006
}

\begin{abstract}
We compare the physical mechanisms involved in the generation and decay of ENSO events in a control (present day conditions) and Scenario (Is92a, IPCC 1996) simulations performed with the coupled ocean-atmosphere GCM ECHAM4-OPYC3. A clustering technique which objectively discriminates common features in the evolution of the Tropical Pacific Heat Content anomalies leading to the peak of ENSO events allows us to group into a few classes the ENSO events occurring in 240 years of data in the control and scenario runs. In both simulations, the composites of the groups show differences in the generation and development of ENSO. We present the changes in the statistics of the groups and explore the possible mechanisms involved.
\end{abstract}

\section{Introduction}

The El Niño-Southern Oscillation (ENSO) dominates the interannual variability in the tropical Pacific atmosphere-ocean system and is the most important mode of variability in the present climate. Paleoclimate records show that ENSO has been a feature of the Earth's climate for at least the past 130 ka (Tudhope et al., 2001), albeit with substantial changes in amplitude and frequency of the associated sea surface temperature anomalies through time (Rodbell et al., 1999; Woodroffe et al., 2003). An increase in ENSO amplitude can be detected in observed data for the last 100 years (Tudhope et al., 2001), with the events of 1982-1983 and 1997-1998 being the most intense in the observed record. Whether this increase in SST anomalies is related to enhanced greenhouse warming (Trenberth and Hoar, 1997) remains an open question. This is partly due to the difficulties in attributing the observed changes to $\mathrm{CO}_{2}$ forcing rather than to interdecadal variability, given the limitations in length and coverage of the observational record.

Correspondence to: W. CabosNarvaez

(william.cabos@uah.es)
In spite of some unrealistic features (Latif et al., 2001; Meehl et al., 2001), simulations with coupled General Circulation Models (CGCM) offer in many cases an adequate representation of present-day-like climatic variability, with the advantage of allowing an excellent data coverage in both space and time. They have thus become an essential tool in climate research and have been used to investigate, among other topics, the evolution of ENSO under different future scenarios. Model studies of greenhouse warming show a variety of results on this issue. For instance, an early simulation with a coarse resolution model (Knutson, 1997), showed little change in ENSO-like activity in spite of a decrease in the mean zonal sea surface temperature gradient. In a coupled simulation with the HadCM2 model, Collins (2000) reports an increased frequency of ENSO events, and a shift in the seasonal signature. In another CGCM simulation, Timmermann et al. (2004) find that the increasing greenhouse gas concentrations induce a more El Niño-like mean state, with more pronounced cold events than warm events. These changes appear to be related to an strengthening of the modelled thermocline (Timmermann et al., 1999).

In this study we investigate the possible effects of increased greenhouse warming on the ENSO-like variability found in the simulation already analyzed by (Timmermann et al., 2004), using a different type of analysis. By means of a clustering technique, we identify the main characteristics of simulated ENSO episodes when the model is forced according to the IS92a IPCC scenario (hereinafter SCR run) and compare the results with a second simulation with present day conditions (hereinafter CTR run). This technique has already been used to analyse ENSO characteristics in a simulation of present day climate variability performed with another coupled GCM, the SINTEX model (AlvarezGarcia et al., 2005). Their study stressed the importance of decadal variability in ENSO generation and impacts. A recent observational study of ENSO impacts, also based on cluster analysis, draws similar conclusions (Potgieter et al., 2005). 


\section{Data}

The ECHAM4/OPYC3 model (Bacher at al., 1998) is a coupled general circulation model. The atmospheric component, ECHAM4, is the fourth version of the European Center Hamburg Atmospheric Model. It is a spectral model that integrates the primitive equations (i. e., the fundamental equations that govern atmospheric motions) under the hydrostatic approximation. In the simulation we analyze here, the atmospheric model variables are represented by spherical harmonics with the expansion truncated at wavenumber 42 (T42), equivalent to a $2.8^{\circ} \times 2.8^{\circ}$ horizontal resolution. For a detailed description of the AGCM and its performance see Röckner et al. (1996).

The OPYC3 model is a layer oceanic model. It has the same zonal resolution as the atmospheric component and a variable resolution in latitude, enhanced to $0.5^{\circ}$ near the equator. A more detailed description of the OPYC model can be found in Oberhuber (1993). The model is flux corrected and shows a good simulation of the seasonal cycle, the statistical characteristics of several climatic indices and the SOI-Niño3 teleconnections. However, the model shows some deficiencies, such as the warmer than observed SST in the tropical Pacific off the South America coast and the overestimation of the biannual component of ENSO.

The total length of both CTR and SCR simulations is 241 years, covering the 1860-2100 period. In the CTR simulation the concentrations of greenhouse gases are fixed to their present-day values. In the SCR experiment the model was forced by increasing greenhouse gases concentrations from 1860 to 1990 and according to the IPPC Scenario IS92a since 1990.

\section{Methodology}

For this study we use a procedure capable of detecting classes of events (groups that share a distinct evolution), following the technique of AlvarezGarcia et al. (2005).

Our method compares the anomaly fields during the development of the events, and groups these on the basis of an objectively computed measure of distance. The algorithm used seeks for common patterns in the development of different episodes. Thus, it does not attend only to their seasonality, amplitude, duration or any other simple condition. This way, our procedure is able to capture peculiarities of the ENSO episodes that are likely to be blurred by linear statistics tools such as Empirical Orthogonal Functions.

In a first step, with the help of the Niño3 time series (SST average anomaly over $\left.\left[150^{\circ} \mathrm{W}-90^{\circ} \mathrm{W}, 5^{\circ} \mathrm{S}-5^{\circ} \mathrm{N}\right]\right)$, we identify the ENSO events occurring in each simulation. We consider an ENSO episode occurs when the index rises over the one standard deviation threshold for at least 3 consecutive months. As an additional condition, we check that the event thus defined is coincidental with extremes in the first Principal Component of the tropical Pacific SST anomalies and in the atmospheric part of the phenomenon, as represented by a model-adapted version of the SOI SLP anomaly index (difference between averaged SLP anomaly over $\left[125^{\circ} \mathrm{E}-\right.$ $\left.135^{\circ} \mathrm{E}, 20^{\circ} \mathrm{S}-10^{\circ} \mathrm{S}\right]$ and $\left.\left[155^{\circ} \mathrm{W}-145^{\circ} \mathrm{W}, 15^{\circ} \mathrm{S}-5^{\circ} \mathrm{S}\right]\right)$.

For the classification, we consider for each event a 16 month segment, formed by 16 spatial maps, that ends with the peak anomaly in the Niño3 index. The choice of this length owes to the two years period dominating the power spectrum of the simulated Niño3 series. We monitor the event's development in the evolution of the heat content (HC) anomalies in the Pacific basin within $15^{\circ} \mathrm{S}$ and $15^{\circ} \mathrm{N}$. The $\mathrm{HC}$ is the energy stored in the upper oceanic layers and is defined in the point with coordinates $(\mathrm{x}, \mathrm{y})$ at time $t$ by the equation

$H C(x, y, t)=\int_{h_{0}}^{0} \rho c_{p} T(x, y, z, t) d z$

where $T$ is the temperature and the integration is carried out from the depth $h_{0}=300 \mathrm{~m}$ up to the ocean surface. To compare different episodes, we compute a distance defined from the spatial correlation between their $\mathrm{HC}$ anomaly patterns in each of those 16 months. This distance serves as the basis for our classification, that is carried out by means of a twostep clustering technique. An initial classification is formed on the basis of a shared near neighbour criterion (Jarvis and Patrick, 1973). These initial classes are characterizad by a composite; they grow by gaining those elements whose distance to the representative composite is below a fixed treshold. The procedure is repeated with an alternate definition of distance, in order to test the robustness of the classification. Before the classification, all (monthly) anomalies are standardized by their corresponding monthly standard deviation. We must take this step in order to adequately compare episodes with different timing. In the case of the SCR run, data have been detrended in order to remove long-term changes (that can be interpreted as variations of the background state) from the anomalies.

Finally, each class is characterized by a composite event, formed by 16 spatial maps, representative of the class behaviour.

An important issue in composite analysis refers to the selection of its significant features. We apply two significance tests: one on the group mean (Terray et al., 2003) and the other on the t-values (Brown and Hall, 1999). This second method makes use of robust estimators of the location (median) and dispersion (interquartilic range) of the elements within a group which allows us to ensure we only retain those features that consistently appear throughout the class. In the following we comment only on features that pass both these tests at a $95 \%$ level.

\section{Results}

We have found 62 warm events in the CTR simulation and 66 warm events in the SCR simulations for the 240 years we analyze. We categorize the warm CTR episodes into three 

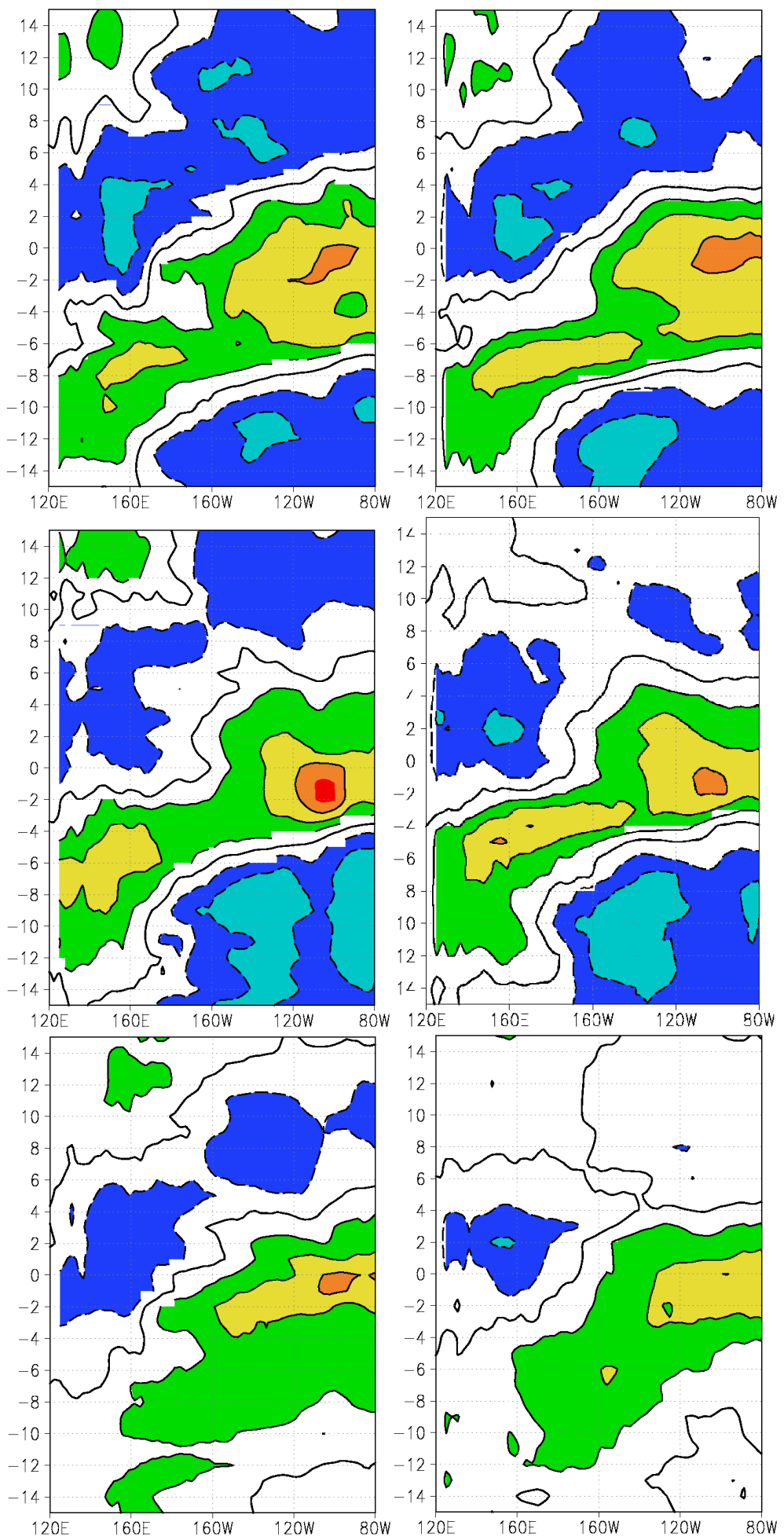

Fig. 1. Hovmueller diagrams of normalized Heat Content $(\mathrm{HC})$ anomalies in the equatorial Pacific for the different classes of events found in the Control (left panels) and Scenario (right panels) runs. In the upper panels we represent the type 1 composites for both runs, the middle panels show the type 2 composites and the lower panels the type 3 composites. The HC anomalies are represented between 15 months before the events peak and 15 months after the peak. The contour interval is 0.5 standard deviations, negative values shaded in blueish colors. The zero label in time marks the month in which the Niño3 Index of the SST composite of a given class peaks. 

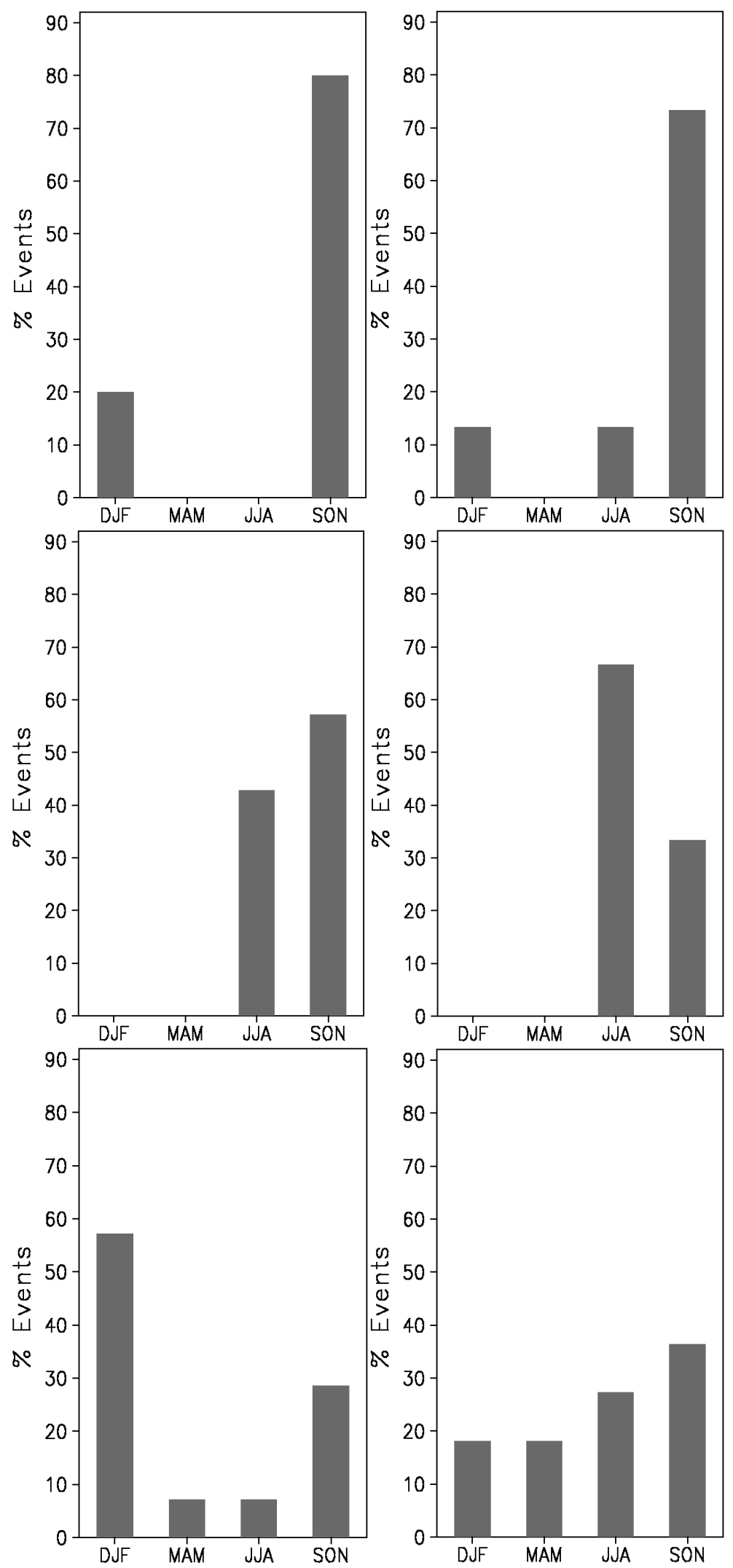

Fig. 2. The seasonal distribution of the peaking months for the events in the different classes identified in the Control (left panels) and Scenario (right panels) runs. As in Fig. 1, the upper panels represent the type 1 composites, the middle panels show the type 2 composites and the lower panels the type 3 composites. 

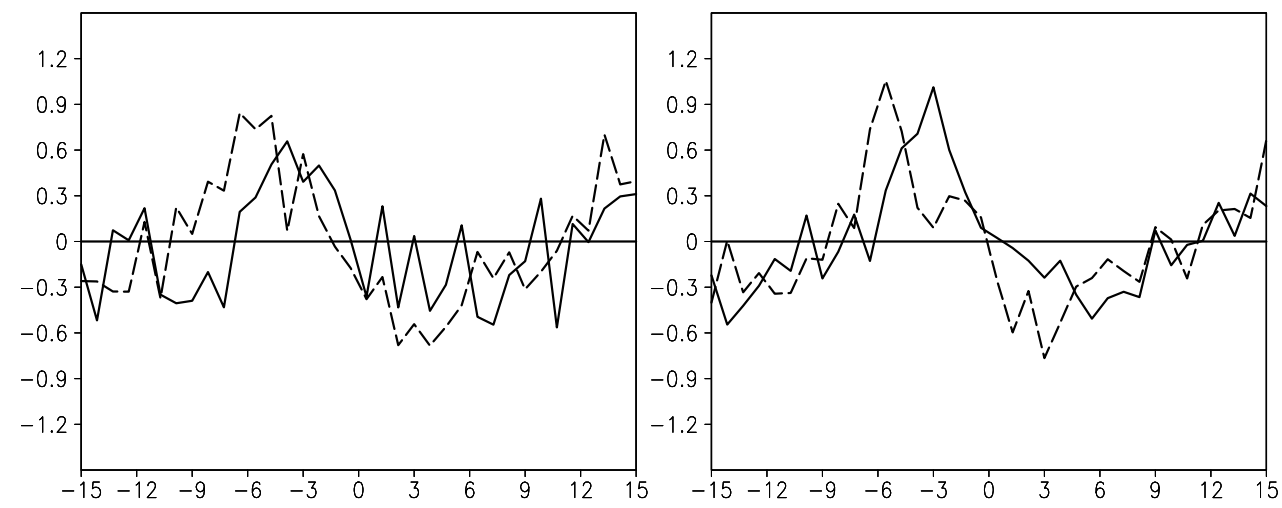

Fig. 3. The surface zonal wind anomalies in the Niño5 region for the control (left panel) and the scenario (right panel) simulations. In both panels values for the class 1 in continous line and for class 2 in dashed.

classes: type CTR1, type CTR2, and type CTR3, respectively accounting for $49 \%, 17 \%$ and $34 \%$ of the classified events (10 warm episodes are not assigned to any group by our method). The SCR events are also distributed into three classes: types SCR1 (36\% of the classified events), SCR2 $(33 \%)$ and SCR3 (31\%). 13 warm episodes are not assigned to any group by our method. Concerning the unclassified elements, most of them are too distant to any of the cluster centers (composites). There are also a few that lie relatively close to a certain class (cluster), in which they might have been included under a less restrictive choice of threshold distances (see methodology above). We have preferred to keep this more restrictive thresholds for the sake of a greater consistency within the clusters.

We will use the equatorial HC (standarized) anomalies time-longitude diagrams of Fig. 1 for a short description of the CTR warm composites.

The CTR1 events are characterized by eastward propagation of warm HC anomalies along the equator towards the eastern Pacific, formerly occupied by cold HC anomalies. This propagation begins about 10 months before the events reach their maximum. The events in this class peak mainly in boreal fall, with most of the events reaching their maximum in November (Fig. 2). Some events in this class peak in the DJF season.

The CTR2 events are in many aspects like those of class CTR1. The development of CTR2 episodes begins two months later than in the case of the CTR 1 events, and the HC anomalies in the east equatorial Pacific have a shorter life span. For class CTR2, there are important positive anomalies in the surface zonal winds over the Niño5 region (120 E140 E, 5 S-5 N) 8 months before the peak in Niño3 Index. The case is quite different with class CTR1, as illustrated by (Fig. 3).

The events in the class CTR2 show a broader distribution in the seasonality of the peaks, that occur in boreal summer and fall (Fig. 2).

In contrast to the evolution of CTR1 and CTR2 events, the western equatorial Pacific $\mathrm{HC}$ anomalies play no part in the generation of episodes of class CTR3. Previous cold HC anomalies in the eastern equatorial Pacific are also absent. Significant HC anomalies can be seen in the eastern equatorial Pacific 8 months before the peak. The events of this class peak preferently in boreal autumn and winter, but a number of them do it in MAM and JJA (Fig. 2), so CTR3 peaks can actually occur in any season. We will not comment on these events, some of whose unrealistic traits remind of features in the simulation of the mean seasonal cycle in the eastern Pacific that need yet to be improved in coupled models.

Turning to the SCR episodes, they are qualitatively similar to their CTR counterparts, as can be seen in Fig. 1. The distinction between classes SCR1 and SCR2, regarding the shorter development of class SCR2 and its tendency to peak earlier than SCR1 (Fig. 2), is somewhat clearer than in CTR. The differences between the type SCR1 and type SCR2 events can be also seen in the evolution of the equatorial thermocline zonal-mean depth anomalies and the Niño4 surface wind anomalies (Fig. 4): the development of SCR2 lags behind that of SCR1 by 2-3 months.

Though the classification essentially yields the same set of classes as in CTR, events distribute among the classes in a different way: the proportion of episodes falling in SCR2 grows (it practically doubles with respect to CTR) mostly at the expense of a decrease in the size of class SCR1. Furthermore, SCR2 events concentrate in the last part of the SCR simulation (Fig. 5), which confirms the linkage between their relative abundance and the enhanced greenhouse gases forcing. Overall, the change detected by our procedure consists of a tendency of model ENSO episodes to shorten their development and peak one season earlier (in JJA rather than in SON) under SCR run conditions.

The greater occurrence of SCR2 events in the last part of the SCR simulation is associated with the modification of the background state. Fig. 6 illustrates the decrease in atmospheric sensitivity in years 201-240 with respect to years $1-40$, as measured by the difference between the regression maps of surface zonal wind anomalies on the Niño3 index. This smaller atmospheric sensitivity might be due to the 

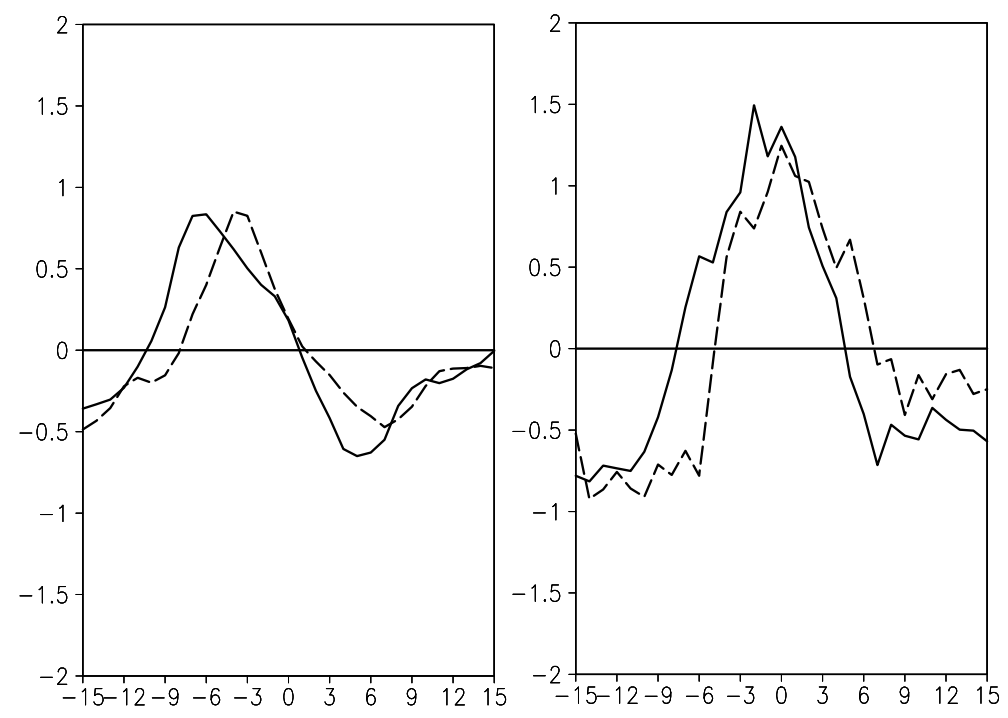

Fig. 4. The Pacific equatorial thermocline zonal-mean depth anomalies(left panel) and the zonal wind velocity Nino4 Index (right panel) for the SCR1 (continous lines) and SCR2 (dashed lines) types.

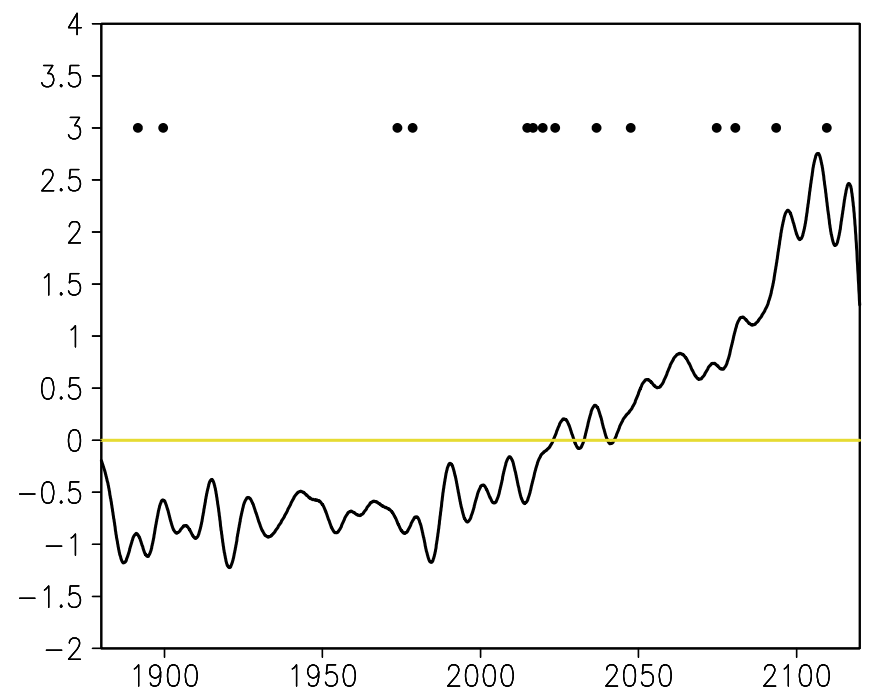

Fig. 5. The first principal component of non detrended Sea Surface Temperature Anomalies for the scenario run and the peaking months for the SCR2 events (filled circles).

reduction of the surface wind convergence in years 201-240 (Fig. 7). Mean wind divergence has been pointed out in several works as a primary factor controlling the atmosphereocean coupling essential to ENSO variability (Tziperman et al., 1997) .

The reduced atmospheric sensitivity in the last part of the SCR run provides an explanation for the abundance of SCR2 episodes: the development of zonal wind anomalies is hindered, and hence the growth of the event, which leads to its premature peaking in JJA. Other changes in the mean state, such as the increase in SST sensitivity to Niño4 (150 E-
$150 \mathrm{~W}, 5 \mathrm{~S}-5 \mathrm{~N}$ ) zonal wind anomalies (Fig. 8), must partially compensate this effect, since the amplitude of SST and $\mathrm{HC}$ anomalies does not diminish.

\section{Conclusions}

A clustering analysis is used to discriminate among the 62 warm ENSO events found in the equatorial Pacific in a global simulation of the climatic variability under present day ( CTR) and future ( SCR) conditions. The analysis detects three different behaviours in the generation and developments of the warm ENSO events in the CTR simulation as well as in the SCR one.

The greatest difference occurs between events of class 1 (CTR1, SCR1) and 2 (CTR2, SCR2) and the events in class 3 (CTR3, SCR3). In the former two classes, there are $\mathrm{HC}$ anomalies in the western equatorial Pacific more than 9 months before the peak in the SST Niño3 Index. These HC anomalies then propagate to the eastern Pacific. As opposed to this, in the latter class there are not any hints of accumulation of $\mathrm{HC}$ anomalies in the western equatorial Pacific, and subsequently no evident eastward propagation prior to the onset of the event.

But there are also significant differences in the way events of class 1 and of class 2 take place. The time span between the eastward propagation of the $\mathrm{HC}$ anomalies and the peak in the SST Niño3 Index is greater (by 2 months) in events of class 1 compared with those in class 2 . Another significant difference is the part that the far western equatorial Pacific plays in the generation of the events. In those of class 2 , there are well developed surface zonal wind anomalies in the Niño5 region 8 months before the peak. The surface zonal wind anomalies generate $\mathrm{HC}$ anomalies that propagate eastwards, a behaviour consistent with the one described by the 


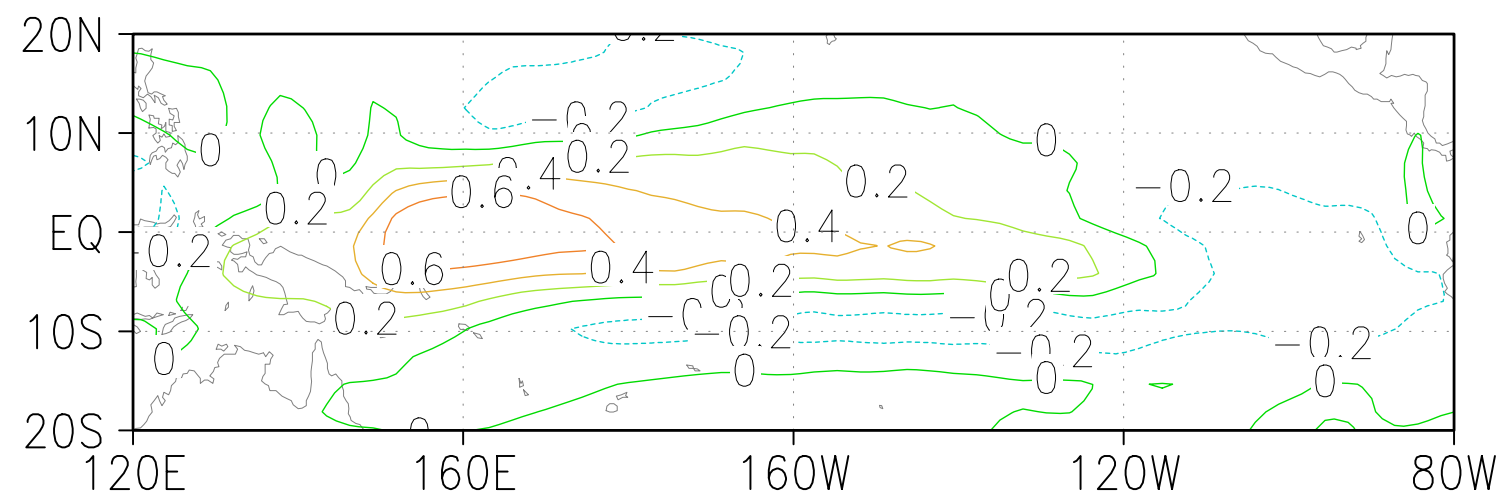

Fig. 6. Difference between the sensitivity of surface zonal wind anomalies to the El Niño3 Sea Surface Temperature anomalies for the last 40 years and the sensitivity for the first 40 years of the scenario run.
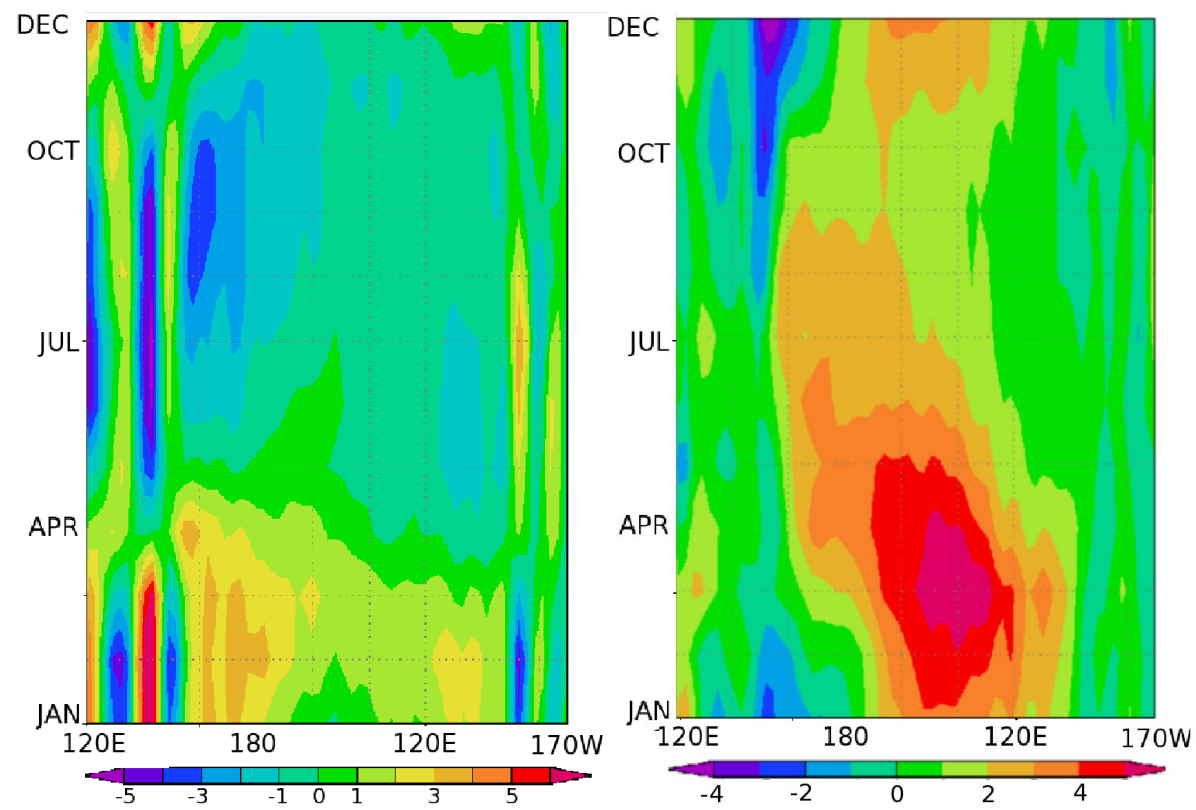

Fig. 7. Seasonal cycle of the wind divergence at the equator for the first 40 years of the scenario run (left panel). Changes in wind divergence at the equator for the last 40 years of the scenario run with respect to the first 40 years (right panel).

"western Pacific oscillator" conceptual model. At this time ( 8 months before the peak) events of class 1 do not present such significant surface zonal wind anomalies in the Niño5 region. The accretion of $\mathrm{HC}$ anomalies in the western equatorial Pacific seems to derive from different mechanisms in classes 1 and 2, which must be one of the factors influencing the differences in their subsequent evolution. Interestingly, zonal wind anomalies over the Niño5 region appear to be important again, now with reversed sign, in the mature stage of class 2 episodes, inmediately (around 3 months) after the peak in the SST Niño3 Index, but yet again not in class 1 (Fig. 3). Lastly, the seasonal signature in the peak of the Niño3 Index is more tightly linked to the end of the year in events of class 1 , a feature observed in the real world.

The three classes are basically maintained under the scenario conditions, with three relevants modifications. One concerns the time span between the eastward propagation of the $\mathrm{HC}$ anomalies and the end of the event, that is shortened by roughly two months for events in the classes 1 and 2 . Another is the distribution of the events among the classes, the number of events in class 2 comparatively increasing. And the last refers to the seasonal signature, that seems to be looser under the scenario conditions.

The relative abundance of episodes of class 2 in the last part of the SCR simulation might be connected with the relevance that wind anomalies over the far western Pacific (likely associated with SST anomalies in the area) appear to have for this type of events: the reduction of mean wind convergence decreases more effectively the sensitivity to SST anomalies in the central-eastern Pacific, where the SST mean state is cooler; this could emphasize the importance of processes in the far western Pacific and favour the generation of events of class 2.

A multimodel extension of this study is planned. 


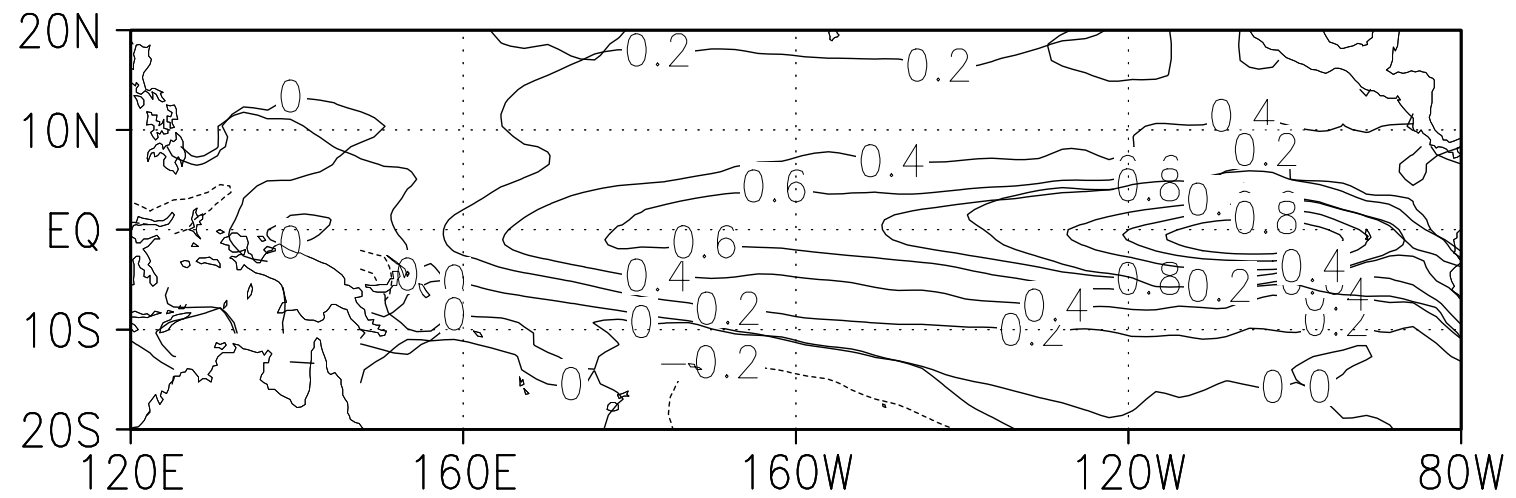

Fig. 8. Difference between the sensitivity of Sea Surface Temperature anomalies to the El Niño4 zonal surface wind anomalies for the last 40 years and the sensitivity for the first 40 years of the scenario run.

Acknowledgements. The authors wish to thank the Max Planck Institute of Meteorology for the ECHAM4-OPYC3 data. This work was supported by the Spanish Ministry of Science and Technology through contract REN2002-02683/CLI.

Edited by: P. Fabian and J. L. Santos

Reviewed by: two anonymous referees

\section{References}

AlvarezGarcia, F., CabosNarvaez, W., and OrtizBeviá, M. J.: An assessment of differences in ENSO mechanisms in a coupled GCM simulation, J. Climate, accepted, 2005.

Bacher, A., Oberhuber, J. M., and Roeckner, E.: ENSO dynamics and seasonal cycle in the Tropical Pacific as simulated by the ECHAM4/OPYC3 coupled general circulation model, Clim. Dyn., 14, 431-450, 1998.

Brown, T. J. and Hall, B. L.: The Use of $t$ Values in Climatological Composite Analyses, J. Clim., 12, 2941-2944, 1999.

Collins, M.: The El Niño Southern Oscillation in the second Hadley Centre coupled model and its response to greenhouse warming, J. Clim., 13, 1299-1312, 2000.

Fedorov, A. V. and Philander, S. G.: A stability analysis of the tropical ocean-atmosphere interactions (bridging the measurements of, and the theory for El Niño), J. Clim., 14, 3086-3101, 2001.

Jarvis, R. A. and Patrick, E. A.: Clustering Using a Similarity Measure based in Near Neighbors, I.E.E. Transactions on Computers, C22, 353-399, 1973.

Knutson, T. R., Manabe, S., and Gu, D.: Simulated ENSO in a Global Coupled OceanAtmosphere Model: Multidecadal Amplitude Modulation and $\mathrm{CO}_{2}$ Sensitivity, J. Clim., 10, 131-161, 1997.

Latif, M., Sperber, K., Arblaster, J., et al.: ENSIP: the El Niño simulation intercomparison project, Clim. Dyn., 18, 255-276, 2001.

Meehl, G. A., Gent, P. R., Arblaster, J. M., Otto-Bliesner, B. L., Brady, E. C., and Craig, A.: Factors that affect the amplitude of El Niño in global coupled models, Clim. Dyn., 17, 515-527, 2001.

Neelin, J. D., Battisti, D. S., Hirst, A. C., Jin, F.-F., Wakata, Y., Yamagata, T., Zebiak, S. E., and Anderson, D.: ENSO theory, J. Geophys. Res., 103, 14 261-14 290, 1998.
Oberhuber, J. M.: Simulation of the Atlantic circulation with a coupled sea ice- mixed layer- isopycnal general circulation model. Part I: Model description, J. Phys. Oceanogr., 23, 808-829, 1993.

Potgieter, A. B., Hammer, G. L., Meincke, H., and Stone, R. C.: Three putative Types of El Niño Revealed by the Spatial Variability in Impact on Australian Wheat Yield, J. Clim., 18, 15661574, 2005.

Röckner, E., Arpe, K., Bengtsson, L., et al.: The atmospheric general circulation model ECHAM4: Model description and simulation of present-day climate, Max Planck Institut für Meteorologie Rep. 218, 94 pp., 1996.

Rodbell, D., Seltzer, G., Anderson, D. M., Abbott, M. B., Enfield, D. B., and Newman, J. H.: A 15000 year record of ENSOdriven alluviation in Southwestern Ecuador, Science, 283, 516520, 1999.

Terray, P., Delecluse, P., Labattu, S., and Terray, L.: Sea surface temperature associations with the late Indian summer monsoon, Clim. Dyn., 21, 593-618, 2003.

Trenberth, K. E. and Hoar, T. J.: The 1990-1995 El Niño-Southern Oscillation event: Longest on record, Geophys. Res. Lett., 23, 57-60, 1997.

Timmermann, A., Oberhuber, J., Bacher, A., Esch, M., Latif, M., and Roeckner, E.: Increased El Niño frequency in a climate model forced by future greenhouse warming, Nature, 398, 694 697, 1999.

Timmermann, A., Jin, F., and Collins, M.: Intensification of the annual cycle in the tropical Pacific due to greenhouse warming, Geophys. Res. Lett., 31, L12208, doi:10.1029/2004GL019442, 2004.

Tudhope, A. W., Chilcott, C. P., McCulloch, M. T., Cook, E. R., Chappell, J., Ellam, R. M., Lea, D. W., Lough, J. M., and Shimmield, G.: Variability in ENSO through a glacialinterglacial cycle, Science, 291, 1511-1517, 2001.

Tziperman, E., Zebiak, S., and Cane, M.: Mechanisms of Seasonal ENSO Interaction, J. Atmos. Sci., 54, 61-71, 1997.

Woodroffe, C. D., Beech, M., and Gagan, M. K.: Midlate Holocene El Nino variability in the equatorial Pacific from coral microatolls, Geophys. Res. Lett., 30(7), 1358, doi:10.1029/2002GL015868, 2003. 